\title{
Analysis of sleep characteristics in post-polio syndrome patients
}

\author{
Tatiana Mesquita e Silva', Gustavo Antonio Moreira², \\ Abrahão Augusto Juviniano Quadros' , Márcia Pradella-Hallinan², \\ Sergio Tufik², Acary Souza Bulle Oliveira'
}

\begin{abstract}
The main post-polio syndrome (PPS) symptoms are new weakness, new atrophy, fatigue, pain and sleep disturbances. Polysomnography is the gold standard for sleep analysis. Objective: To analyze sleep patterns in PPS patients. Method: Sixty patients (mean age $46.8 \pm 11.3$ years) at the Federal University of São Paulo (UNIFESP/EPM) complaining of sleep disturbances were evaluated by means of polysomnography, performed at the Sleep Institute. Results: Sleep efficiency was lower due to high sleep latency and arousal index. The apnea and hypopnea index (AHI) and the periodic limb movements (PLM) index were higher. Sleep architecture was also impaired. There were no abnormalities of oxygen saturation, carbon dioxide levels, respiratory rate or heart rate. Conclusion: New post-polio sleep disturbances were isolated symptoms. It appears that these symptoms were not due to post-polio features, but rather, that they were due to dysfunction of the surviving motor neurons in the brainstem. Abnormal dopamine production, which is responsible for many sleep-related breathing disorders and abnormal movements, may also have been implicated in the present findings. Key words: sleep, polysomnography, post-polio syndrome.
\end{abstract}

\section{Análise das características do sono em pacientes com síndrome pós-poliomielite}

\section{RESUMO}

Dentre as manifestações clínicas da síndrome pós poliomielite (SPP) destacam-se nova fraqueza, fadiga, dor, nova atrofia e transtornos do sono. A polissonografia de noite inteira permanece sendo padrão ouro para análise do sono e diagnóstico de transtornos do sono. Objetivo: Verificar os transtornos de sono nos pacientes com SPP. Método: 60 pacientes com SPP (media de idade 46,8 8 11,3 anos), da UNIFESP/EPM, que apresentavam queixas sobre sono realizaram uma noite de polissonografia no Instituto do Sono. Resultados: A eficiência do sono é diminuída em decorrência do aumento da latência do sono e do índice de despertar. $\mathrm{O}$ índice de apnéia e hipopnéia (IAH) e o índice de movimentos periódicos dos membros (iPLM) estão aumentados. A arquitetura do sono é prejudicada por essas alterações. Não há alterações da saturação da oxi-hemoglobina, do gás carbônico exalado, da freqüência respiratória e cardíaca. Conclusão: Novas alterações do sono são sintomas isolados desta população. Parece que esses sintomas não ocorrem devido a outras características da SPP, mas decorrem de disfunções nos neurônios do tronco encefálico e alterações da produção de dopamina que provocam os distúrbios respiratórios do sono e os movimentos periódicos dos membros.

Palavras-chave: sono, polissonografia, síndrome pós-poliomielite.

\section{Correspondence}

Tatiana Mesquita e Silva

Rua Estado de Israel 899

02144-002 São Paulo SP - Brasil

E-mail: tatimsilva@gmail.com

Received 17 July 2009

Received in final form 1 February 2010

Accepted 11 February 2010
The post-polio syndrome (PPS) describes new neuromuscular symptoms appearing at least 15 years after achieving clinical stability of patients who had previously presented poliomyelitis. The main clinical manifestations of PPS are new weakness, fatigue, pain, intolerance of cold temperatures, new atrophy and sleep disturbances ${ }^{1,2}$.

Universidade Federal de São Paulo / Escola Paulista de Medicina, São Paulo SP, Brazil: 'Department of Neurology: ${ }^{2}$ Department of Psychobiology. 
The most frequent sleep disturbances in PPS patients are obstructive sleep apnea (OSA) and period limb movements (PLM). Overall, these are responsible for the poor sleep quality. The frequency of sleep-disordered breathing (SDB) seems to be higher in patients with previous polio than in the general population ${ }^{3}$.

From the anatomical and pathological points of view, the bulb region in the brainstem could be affected by the poliovirus, thereby leading to impairment of the sleep regulator center. This may have a direct relationship to the sleep-related clinical manifestations of PPS ${ }^{4}$.

Our clinical experience led us to hypothesize that PPS patients with sleep complaints might present SDB or PLM, and that their physical symptoms might be exacerbated due to this disorder. Therefore, sleep characteristics were analyzed and correlated with symptoms of pain, fatigue, headache and sleep complaints, including daily hypersomnolence.

\section{METHOD}

The present report is a descriptive analytical study, carried out among patients presenting previous poliomyelitis sequelae. PPS had been diagnosed over one year earlier. This study was approved by the Research Ethics Committee of the Federal University of Sao Paulo, under number 0152/05, in March 2005.

From January 2003 to December 2006, 199 patients with previous poliomyelitis underwent both a clinical evaluation at the Neuromuscular Sector of the Federal University of São Paulo (UNIFESP/EPM) and a polysomnographic evaluation at the Sleep Institute of UNIFESP/ EPM. From this group of 199 patients, 166 (80.4\%) had had PPS diagnosed and were selected to enter the study. In a randomized manner, 60 patients were selected for a clinical evaluation. All of them signed the free and informed consent statement. Fatigue (fatigue severity scale), pain (visual analog scale) and daily somnolence (Epworth sleepiness scale) were evaluated. Intolerance to cold, memory and concentration complaints and headache were also investigated. After this evaluation, these patients underwent a whole-night polysomnographic evaluation.

The polysomnographic evaluation was conducted at night, in a dark and silent room. The sleep data were recorded from $10 \mathrm{pm}$ to $7 \mathrm{am}$. The following parameters were measured and recorded by a computer system (Alice Respironics ${ }^{\circ}$, Marieta, GA, USA): [1] electroencephalogram (C3/A2, C4/A2, O1/A2, O2A1); [2] left and right electrooculogram; [3] submentonian electromyography; [4] anterior tibialis electromyography; [5] electrocardiography; [6] abdominal and thoracic movement, with electric transducer; [7] oral and nasal flow and / or [8] nasal pressure cannula; [9] body position sensor; [10] partial pressure of carbon dioxide at end of expiration $\left(\mathrm{P}_{\mathrm{ET}} \mathrm{CO}_{2}\right)$; and [11] percutaneous oxy-hemoglobin saturation $\left(\mathrm{SpO}_{2}\right)$ (Ohmeda ${ }^{\circ}$ Biox 3740 Louisville, CO, USA).

The sleep stage was established using the Rechtschaffen and Kales criteria ${ }^{5}$. Total register time (TRT), total sleep time (TST), sleep latency (SL), sleep efficiency (SE), REM-sleep latency, arousal index, stage changes, percent of TST for stages 1, 2, 3 and 4 of non-REM sleep and REM sleep were assessed. Oxy-hemoglobin percutaneous saturation while awake, non-REM and REM sleep, Nadir, carbon dioxide partial pressure at the end of expiration $\left(\mathrm{P}_{\mathrm{ET}} \mathrm{CO}_{2}\right)$ while awake, non-REM and REM sleep, and peak $\mathrm{CO}_{2}$ were also assessed. The variables of SDB (number of obstructive apnea, central apnea, mixed apnea, hypopnea, and apnea and hypopnea index (AHI) were measured. Sleep apnea syndrome was defined as: mild, with AHI ranging from 5 to 15 events per hour; moderate, when ranging from 16 to 30 events per hour; or severe, with more than 31 events per hour. Periodic limb movements (PLM) were defined as mild when AHI ranged from 5 to 24 events per hour; moderate when it ranged from 25 to 49 events per hour; or severe, with more than 50 events per hour.

Obstructive sleep apnea (OSA) was defined as an upper airway blockage during sleep without bulb impairment. Obstructive sleep apnea syndrome (OSAS) was classified as: mild, when AHI ranged from 5 to 14 events per hour; moderate, when AHI ranged from 15 to 29 events per hour; or severe, when AHI was greater than 30 events per hour. For AHI greater than 14 events per hour, BiPAP was indicated.

The severity of periodic limb movements index (PLMi) was classified by means of the polysomnographic examination as: mild, PLM from 5 to 24 events per hour; moderate, PLM from 25 to 49 events per hour and severe, PLM higher than 50 events per hour.

A group totaling 60 patients was studied: 39 were female, i.e. 65\%; mean age 46.8 years (ranging from 32 to 59 years); median age 47 years for men and 48 years for women (Table 1). All patients fulfilled the post-polio criteria from the 2001 conference.

\section{Statistical analysis}

Descriptive analysis was used for comparisons of percentages, for odds calculation, as well as for mean and median values, with the respective standard deviation. The chi-square test $\left(\chi^{2}\right)$ was used for categorical data.

The continuous variables were tested for parametric distribution using the Kolmogorov-Smirnov test.

Results were considered to be statistically significant for an alpha error of $5 \%(\mathrm{p}<0.05)$. The calculations were done and graphs were made using the STATISTICA software, version 5.1 (Statsoft, Inc, Tulsa, OK, USA) and Microsoft Excel (Version 2003 SP2, Portland, OR, USA). 
Table 1. Social and demographic characteristics of post-polio syndrome patients.

\begin{tabular}{lcc}
\hline & N & $\%$ \\
\hline Age, years & $46.8 \pm 11.3$ & \\
Sex & & \\
$\quad$ Male & 21 & 35 \\
Female & 39 & 65 \\
Total & 60 & 100 \\
Race & & 85 \\
Caucasian & 51 & 5 \\
Black & 3 & 10 \\
Asian & 6 & \\
Total & 60 & 100 \\
\hline
\end{tabular}

\section{RESULTS}

This group of patients presented lower sleep efficiency, higher arousal index, higher REM latency and a larger number of stage changes. PLM index $>5$ per hour and AHI $>5$ per hour were present in most patients. The mean level of oxy-hemoglobin saturation $\left(\mathrm{SpO}_{2}\right)$ was between $90 \%$ and $95 \%$, while the $\mathrm{SpO}_{2}$ low values were between
$58 \%$ and $96 \%$. The mean carbon dioxide partial pressure $\left(\mathrm{P}_{\mathrm{ET}} \mathrm{CO}_{2}\right)$ was $35 \mathrm{mmHg}$, with a peak at $40 \mathrm{mmHg}$. Respiratory rates were lower than 16 breaths per minute, while the heart rate was between 74 and 85 beats per minute (Table 2).

The symptoms of intolerance to cold, fatigue and sleep abnormalities were the most frequent findings in $73.3 \%$, $80 \%$ and $78.3 \%$ of patients, respectively. Pain and headache were present in more than $50 \%$ of the patients, while other symptoms were less frequently observed (Table 3 ).

\section{DISCUSSION}

The present study was performed prospectively. The data and results were analyzed by the same person. Ten patients (16.6\%) used non-invasive nocturnal ventilation during testing, due to obstructive sleep apnea (OSA). Bach $^{6}$ reported that $15 \%$ of PPS patients needed nocturnal non-invasive ventilation (NNIV) because of higher AHI, oxy-hemoglobin desaturation and $\mathrm{CO}_{2}$ retention.

The PPS sleep characteristics are similar to other neuromuscular disorders affecting the sleep profile, but PPS has some particular features.

Table 2. Sleep quality of post-polio syndrome patients.

\begin{tabular}{|c|c|c|c|}
\hline Polysomnographic parameters & Mean $\pm S D$ & Maximum & Minimum \\
\hline Total sleep time, min & $324.9 \pm 73.3$ & 461 & 163 \\
\hline Sleep efficiency, \% & $69.2 \pm 14.9$ & 98.6 & 34.8 \\
\hline Sleep latency, min & $40.1 \pm 35.1$ & 163 & 0 \\
\hline REM sleep latency, min & $121.7 \pm 71.9$ & 353.5 & 2.5 \\
\hline Arousal index, $\mathrm{n} / \mathrm{h}$ & $9.9 \pm 11.5$ & 53.6 & 0.9 \\
\hline Stage changes, $\mathrm{n} / \mathrm{h}$ & $72.7 \pm 25.2$ & 170 & 38 \\
\hline PLM, n & $45.7 \pm 105.3$ & 697 & 0 \\
\hline PLM, n/h & $5.3 \pm 11.1$ & 44.7 & 0 \\
\hline $\mathrm{SpO}_{2} \mathrm{REM}, \%$ & $94.2 \pm 2.5$ & 98 & 84 \\
\hline $\mathrm{SpO}_{2} \mathrm{NREM}_{1} \%$ & $94.1 \pm 2.3$ & 97 & 85 \\
\hline $\mathrm{SpO}_{2}$ baseline, $\%$ & $94.2 \pm 2.1$ & 98 & 87 \\
\hline Nadir $\mathrm{SpO}_{2}, \%$ & $86.5 \pm 8.6$ & 96 & 58 \\
\hline $\mathrm{P}_{\mathrm{ET}} \mathrm{CO}_{2}$ awake, $\mathrm{mmHg}$ & $33.8 \pm 4.3$ & 45 & 25 \\
\hline $\mathrm{P}_{\mathrm{ET}} \mathrm{CO}_{2} \mathrm{REM}, \mathrm{mmHg}$ & $34.4 \pm 5.3$ & 44 & 18 \\
\hline $\mathrm{P}_{\mathrm{ET}} \mathrm{CO}_{2} \mathrm{NREM}, \mathrm{mmHg}$ & $34.4 \pm 4.3$ & 44 & 23 \\
\hline $\mathrm{PicO} \mathrm{CO}_{2}, \mathrm{mmHg}$ & $41.8 \pm 4.4$ & 53 & 35 \\
\hline $\mathrm{AHI}, \mathrm{n} / \mathrm{h}$ & $6.2 \pm 14.5$ & 80.4 & 0 \\
\hline Number of obstructive apnea, $\mathrm{n} / \mathrm{h}$ & $19.2 \pm 54.9$ & 261 & 0 \\
\hline Number of central apnea, $\mathrm{n} / \mathrm{h}$ & $1.1 \pm 3.9$ & 23 & 0 \\
\hline Number of mix apnea, $\mathrm{n} / \mathrm{h}$ & $1.4 \pm 6.5$ & 41 & 0 \\
\hline Hypopnea, n/h & $13.4 \pm 26.3$ & 181 & 0 \\
\hline Breathing rate awake, rpm & $14.5 \pm 3.7$ & 24.9 & 12 \\
\hline Breathing rate $\mathrm{REM}$, rpm & $14.3 \pm 4.5$ & 23 & 12.5 \\
\hline Breathing rate NREM, rpm & $15.9 \pm 10$ & 81.5 & 12.7 \\
\hline Heart rate awake, bpm & $84.4 \pm 30.3$ & 89.6 & 53.2 \\
\hline Heart rate REM, bpm & $75.4 \pm 19.6$ & 86.4 & 50.1 \\
\hline Heart rate NREM, bpm & $74.7 \pm 22$ & 88.5 & 46.9 \\
\hline
\end{tabular}


Table 3. Symptoms of post-polio syndrome patients.

\begin{tabular}{lccc}
\hline Symptoms & Patients, $\mathbf{n}(\%)$ & Maximum & Minimum \\
\hline Fatigue (FSS >28) & $48(80)$ & 63 & 9 \\
Pain (VAS >5) & $34(56)$ & 10 & 1 \\
Morning headache (yes) & $42(70)$ & - & - \\
Cold intolerance (yes) & $50(83)$ & - & - \\
Memory impairment (yes) & $27(45)$ & 2 & 22 \\
Daily hyper somnolence (Epworth >12) & $29(48)$ & 60 & 12 \\
Sleep impairment (Mini-sleep >30) & $47(78)$ & 7 & 1 \\
Daily hypersomnolence (Stanford >4) & $10(16)$ & - \\
\hline
\end{tabular}

In the present report, sleep efficiency (SE) was decreased (lower than 85\%) in 44 of the 60 patients, ranging from $67.4 \%$ (patients using non-invasive ventilation) to 69.5\% (patients not using non-invasive ventilation). This reduced SE is likely to reflect the arousals during sleep (average of 10 events per hour), as well as sleep-related disordered breathing and PLM, which are both frequent in PPS populations. Abnormal movements during sleep have been described in patients with PPS. From polysomnographic examination, it was observed that these movements were diversified, and were present in $63 \%$ of the PPS patients ${ }^{7}$.

According to Steljes et al. ${ }^{8}$, the sleep efficiency of PPS patients with sleep complaints was $52.2 \%$, the arousal index was 30.5 events per hour, AHI was 56.4 events per hour and the mean $\mathrm{SpO}_{2}$ during the night was $90 \%$. According to other authors, the PPS patients sleep efficiency was $89.3 \%$, with a high PLM index reported in $24.8 \%$ of the patients?

Respiratory impairment (AHI) was observed in the present study, ranging from 0 to 80.4 (mean of $6.2 \pm 14.5$ ) events per hour. On the other hand, oxy-hemoglobin saturation and exhaled $\mathrm{CO}_{2}$ did not show changes in this population.

For the present PPS population, the abnormalities in the polysomnographic examination and in the sleep architecture indicated decreased sleep quality. This was evident from the greater time spent in superficial sleep stages $(73.6 \%$ of TST), to the detriment of slow-wave sleep (7.8\% of TST) and REM sleep (18.7\% of TST). These findings were similar to those of Hsu et al. ${ }^{8}$, who reported that $71.1 \%$ of TST was spent in superficial sleep stages, $14.7 \%$ of TST in slow-wave sleep and 14.1\% of TST in REM sleep.

The difficulties observed among PPS patients regarding deepening of sleep and entering REM sleep are believed to be due to impaired reticular formation due to the poliovirus. This difficulty seems to be more pronounced in patients with bulb injury ${ }^{10}$.

It has been reported that $13 \%$ of PPS patients presented difficulties in remaining asleep, $8 \%$ had difficul- ty in falling asleep and 25\% had PLM, which can also impair sleep deepening and, at the same time, can facilitate arousal ${ }^{11}$.

The results from the present study showed the prevalence of PPS symptoms to be as follows: cold intolerance appeared as a complaint among $83.3 \%$ of the patients, fatigue in $80 \%$, sleep abnormalities in $78.3 \%$, chronic headache in $70 \%$ and pain in $56.6 \%$.

Cold intolerance is reported to be very prevalent in the Brazilian population as a complaint (in $46 \%{ }^{12}$ ) and in $69.8 \%$ of the worldwide PPS population ${ }^{13}$. This prevalent symptom can decrease the sensation of muscle strength in these individuals ${ }^{14}$.

Fatigue is a frequent and debilitating symptom of PPS, and its prevalence ranges from $48 \%^{15}$ to $87 \%{ }^{16,17}$ For the Brazilian PPS population, the prevalence of fatigue ranges from $66 \%{ }^{18}$ to $77.5 \%{ }^{12}$. About $41 \%$ of PPS patients report that fatigue significantly influences the execution of tasks, while $25 \%$ of the patients report that fatigue influences their personal care activities. It has been reported that fatigue was provoked or exacerbated by intense physical activity and by emotional stress in $92 \%$ and $61 \%$ of the participants, respectively. ${ }^{13}$ The exacerbation of fatigue carries complications, mainly affecting strength, thereby leading to pain and inducing sleep abnormalities ${ }^{19}$.

Poor quality of sleep was reported by about $70 \%$ of the Brazilian PPS patients in a previous study ${ }^{12}$. The main reason for this finding seems to be sleep-related disturbanc$\mathrm{es}^{8}$. In a report on over 600 PPS patients, $63 \%$ reported that their muscles jumped during their sleep, leading to fragmented sleep in $52 \%$ of these patients?

Morning headache is, in most cases, caused by bad encephalic oxygenation and $\mathrm{CO}_{2}$ retention during sleep. Up to $45 \%$ of Brazilian PPS patients reported this symptom and correlated it with disordered breathing during sleep ${ }^{12}$. However in the present study, no $\mathrm{CO}_{2}$ retention or $\mathrm{O}_{2}$ desaturation was observed, but $70 \%$ of the patients reported this symptom because of apnea and PLM. Pain was a symptom reported by $43 \%$ to $80 \%{ }^{17}$ of PPS patients. Studies in Brazil have shown different prevalences 
for muscle and joint pain $(76 \% \text { and } 79 \% \text {, respectively })^{12}$. Other reports have shown joint pain rates of $55 \%$ to $79 \%$, thereby leading to difficulty in falling asleep and maintaining sleep, and decreasing sleep efficiency ${ }^{20}$. Thirtyfour of the patients evaluated here (56\%) reported muscle and/or joint pain, and these results were similar to those obtained in studies conducted both in Brazil and elsewhere. Ninety percent of these patients were able to walk independently or with the use of canes, walkers or orthoses, and most of them were still working. However, all of them made use of energy conservation techniques. Trojan and Cashman ${ }^{21}$ reported that $50 \%$ of PPS patient presented chronic muscle and joint pain that might be related to fibromyalgia.

Van Kralingena ${ }^{11}$ reported that $35 \%$ of PPS patients with body mass index (BMI) over $45 \mathrm{~kg} / \mathrm{m}^{2}$ presented OSAS. In epidemiological studies, the prevalence of OSAS in healthy adults of the same age as the population of the present study was $15 \%{ }^{22}$. Duran et al. ${ }^{23}$ estimated that the prevalence of OSAS was 15\% among males aged 30 to 70 years. Among women, this prevalence was $7 \%$, and among the elderly, the prevalence increased to $37.5 \%{ }^{24}$. The high prevalence of OSAS among postmenopausal women might be due to the absence of estrogens and progesterone, i.e. the hormones that increase upper airway permeability and respiratory function ${ }^{25}$. Therefore, PPS patients present higher AHI than do general populations of adults, and lower AHI than do the elderly.

Kalpakjan ${ }^{26}$ studied postmenopausal women with PPS and found exacerbation of daily hypersomnolence, along with psychological abnormalities, compared with postmenopausal women without polio sequelae. In the present study, 25 patients (41.5\%) were women aged between 47 and 59 years, which has to be taken into consideration, since some PPS symptoms may be exacerbated by the menopause.

Obstructive sleep apnea syndrome (OSAS) is caused by obstruction of the upper airway, due to increase volumes of tissue around the airways, tonsils and adenoids, or increased uvula size ${ }^{27}$. Patients with PPS and OSAS may present respiratory problems, sleep arousals and decreased oxygen saturation due to brainstem lesions caused by the poliovirus. Dean et al. ${ }^{28}$ reported that PPS patients' polysomnographic examinations showed unaltered sleep architecture, but presented increased AHI (bulbar and non-bulbar polio), due to reduction of brainstem control during non-REM sleep. Iber et al. ${ }^{29}$ reported that $90 \%$ of PPS patients presented OSA, while $10 \%$ presented CSA and MSA.

According to Hsu et al. ${ }^{9}, 54.2 \%$ of PPS patients had OSAS, $20 \%$ had chronic alveolar hypoventilation $(\mathrm{CAH})$ and $25.8 \%$ had both diagnoses. The symptoms of dyspnea, daily hypersomnolence, insomnia and new weakness were more frequent in patients with $\mathrm{CAH}$ than in patients with OSAS. Sleep-disordered breathing (SDB) seems to be a late sequela of poliomyelitis, and therefore clinical evaluations on PPS patients should include information on sleep.

$\mathrm{Bach}^{3,6}$ reported that one third of PPS patients made use of continuous positive airway pressure (CPAP) noninvasive ventilation, and $14.5 \%$ of polio sequela patients used bi-level positive airway pressure (BiPAP) because of chronic alveolar hypoventilation (CAH). Forced vital capacity (FVC) can decrease by $1.9 \%$ a year in PPS patients because of fatigue and muscle weakness, which may ultimately result in impaired concentration and memory, as well as decreased sexual desire. Respiratory muscle dysfunction, scoliosis and obesity can highlight these complications. Ten PPS patients in the present study made use of BiPAP for OSAS, oxy-hemoglobin desaturation, hypercapnia and hypoventilation.

Decreased oxy-hemoglobin saturation during the night, when associated with hypercapnia, can predict morning headache. PPS patients may present decreased third and fourth-stage sleep, increased micro-arousals and PLM $^{21,30}$, restless leg syndrome and insomnia ${ }^{30}$, and may frequently feel chronic pain.

Thirteen patients (21.6\%) in the present study had a PLM index $>5$ events per hour and six of them (15\%) had a PLM index $>15$ events per hour, as well as daily hypersomnolence (mean Epworth=12). An increased PLM index often has consequences, such as difficulties in deepening sleep, increased arousals, inefficient sleep, leg tiredness and peripheral fatigue. An epidemiological study by Pennestri et al. ${ }^{31}$ showed an average PLM index in healthy adults (40 to 59 years old) ranging from 10 to 12 events per hour. Pallesen et al. ${ }^{32}$ reported that patients with $P L M<5$ event per hour only felt mild daily somnolence.

Bruno et al. ${ }^{7}$ described leg movements in PPS patients as myoclonus, ballistic movements and PLM, while Hornyak et al. ${ }^{33}$ reported that the presence of these movements could decrease sleep efficiency, and increase both the number of arousals and the proportion of stage-one sleep. Neubauer ${ }^{24}$ concluded that the older the patient was, the higher the PLM index would be.

Siegel et al. ${ }^{10}$ reported that REM sleep latency might be increased through long-term necessity to recruit motor neurons of the pontine tegument after polio damage. Bourke and Gibson ${ }^{34}$ reported that TST and sleep efficiency were both decreased, probably as a reflection of muscle weakness, arousals and increased duration of stage one, especially among PPS patients with sleep-disordered breathing.

The treatments for sleep disturbances have already been described in the literature. Treating sleep disturbances may lead to an improvement in the quality of life, thereby decreasing the intensity of many limiting symptoms. 
In conclusion, the sleep quality of PPS patients was decreased due to impairment of sleep efficiency, arousals, changes in the different sleep stages, increased PLM index, OSAS, and increased percentages of stages 1 and 2 . The main PPS symptoms were intolerance to cold (83.3\%), fatigue (80\%), sleep impairment (78.3\%), headache (70\%) and pain (56.6\%).

Polysomnographic evaluation is useful and essential for PPS patients with SDB and other impairments of sleep quality.

ACKNOWLEDGMENTS - To the Sleep Institute, for providing the polysomnographic examinations.

\section{REFERENCES}

1. Dalakas MC. Post-polio syndrome 12 years later: how it all started. Ann N Y Acad of Sci 1995;753:11-18.

2. Halstead LS, Rossi CD. Post-polio syndrome: clinical experience with 132 consecutive outpatients. Birth Defects Orig Artic Ser 1987;23:13-26.

3. Bach JR, Tilton M. Pulmonary dysfunction and its management in post-polio patients. Neuro Rehabil 1997;8:139-153.

4. Bodian D. Poliomyelitis: pathological anatomy. In: Poliomyelitis: papers and discussions presented at the first international poliomyelitis conference Lippincott, Philadelphia;1949.

5. Rechtschaffen A, Kales A (Eds). Los Angeles: Brain Information Service/Brain Research Institute, University of California; 1968. A manual of standardized terminology, techniques and scoring system of sleep stages in human subjects.

6. Bach JR. Pulmonary dysfunction and sleep disordered breathing as post-polio sequelae: evaluation and management. Orthopedics 1991;14:1329-1337.

7. Bruno RL. Abnormal movements in sleep as a post-polio sequelae. Am Phys Med Rehabil 1998;77: 339-343.

8. Steljes DG, Millar TW. Sleep in post-polio syndrome. Chest 1990;98:133-140.

9. Hsu AA, Staats BA. Postpolio sequelae and sleep-related disordered breathing. Mayo Clin Proc 1998;73:216-224.

10. Siegel H, McCutchen C, Dalakas MC, et al. Physiologic events initiating REM sleep in patients with the postpolio syndrome. Neurology 2000;52:516-522.

11. Van Kralingena K, Kanterb W, Grootb GH, et al. Assessment of sleep complaints and sleep-disordered breathing in a consecutive series of obese patients. Respiration 1999;66:312-316.

12. Quadros AAJ. Síndrome pós-polio: uma nova doença velha. Dissertação. Escola Paulista de Medicina da UNIFESP;São Paulo 2005.

13. Bruno RL, Johnson JC, Berman WS. Vasomotor abnormalities as post-polio sequelae: functional and clinical implications. Orthopedics 1985;8:865-869.

14. Agre JC, Rodriquez AA, Sperling KB. Symptoms and clinical impressions of patients seen in a postpolio clinic. Arch Phys Med Rehabil 1989;70:367-370.

15. Cosgrove JL, Alexander MA, Kitts EL, Swan BE, Klein MJ, Bauer RE. Late effects of poliomyelitis. Arch Phys Med Rehabil 1987;68:4-7.
16. Bruno RL, Frick NM. The psychology of polio as prelude to post-polio sequelae: behavior modification and psychotherapy. Orthopedics 1991;14: 1185-1193.

17. Chetwynd J, Botting C, Hogan D. Postpolio syndrome in New Zealand: a survey of 700 polio survivors. N Z Med J 1993;106:406-408.

18. Oliveira ASB, Maynard FM. Síndrome pós-poliomielite: aspectos neurológicos. Rev Neurociencias 2002;10:31-34

19. Gonzalez H, Stibrant Sunnerhagen K, Sjöberg I, Kaponides G, Olsson T, Borg K. Intravenous immunoglobulin for post-polio syndrome: a randomised controlled trial. Lancet Neurol 2006;5:493-500

20. Jubelt B, Cashman NR. Neurological manifestations of the post-polio syndrome. Crit Rev Neurobiol 1987;3:199-220.

21. Trojan DA, Cashman NR. Fibromyalgia is common in a postpoliomyelitis clinic. Arch Neurol 1995;52:620-624.

22. Young T, Palta M, Dempsey J, Skatrud J, Weber S, Badr S. The occurrence of sleep-disordered breathing among middle-aged adults. N Engl J Med 1993;328: 1230-1235.

23. Durán J, Esnaola S, Rubio R, Iztueta A. Obstructive sleep apnea-hypopnea and related clinical features in a population-based sample of subjects aged 30 to 70 yr. Am J Respir Crit Care Med 2001;163:685-689.

24. Neubauer DN. Sleep problems in the elderly. Am Acad Family Physicians 1999:58:2551-2560.

25. Kalpakjian CZ, Quint EH, Tate DG, Roller S, Toussaint LL. Menopause characteristics of women with physical disabilities from poliomyelitis. Maturitas 2007;56:161-172.

26. Kalpakjian CZ, Quint EH, Toussaint LL. Menopause and post-polio symptoms as predictors of subjective sleep disturbance in poliomyelitis survivors. Climateric 2007;10:51-62

27. Nery LE, Fernandes ALG, Perfeito JAL. Síndrome da apnéia e hipopnéia do sono obstrutiva (SAHSO). Guia de Pneumologia: quias de medicina ambulatorial e hospitalar da UNIFESP / Escola Paulista de Medicina. 1ª Ed. Editora Manole, 2007.

28. Dean AC, Graham BA, Dalakas M, Sato S. Sleep apnea in patients with postpolio syndrome. Ann Neurol 1998;43:661-664.

29. Iber C, Davies SF, Mahowald MW. Nocturnal rocking bed therapy: improvement in sleep fragmentation in patients with respiratory muscle weakness. Sleep 1989;12:405-412.

30. Saletu B, Anderer P, Saletu M, Hauer C, Lindeck-Pozza L, Saletu-Zyhlarz G. EEG mapping, psychometric, and polysomnographic studies in restless legs syndrome (RLS) and periodic limb movement disorder (PLMD) patients as compared with normal controls. Sleep Med 2002;3:35-42.

31. Pennestri MH, Whittom S, Adam B, Petit D, Carrier J, Montplaisir J. PLMS and PLMW in healthy subjects as a function of age: prevalence and interval distribuition. Sleep 2006;29:1183-1187.

32. Pallesen S, Nordhus IH, Omvik S, Sivertsen B, Tell GS, Bjorvatn B. Prevalence and risk factors of subjective sleepiness in the general adult population. Sleep 2007;30:619-624.

33. Hornyak M, Kopasz M, Feige B, Riemann D, Voderholzer U. Variability of periodic leg movements in various sleep disorders: implications for clinical and pathophysiologic studies. Sleep 2005;28:331-335.

34. Bourke SC, Gibson GJ. Sleep and breathing in neuromuscular disease. Eur Respir 2002;12:1194-1201. 